\title{
Making Personal Libraries More Public: A Study of the Technical Processing of Personal Libraries in ARL Institutions ${ }^{1}$
}

THE PERSONAL Libraries of writers, scholars, artists, and other well-known people occupy an ambiguous place within the special collections areas of libraries that assume custody of them after their owners' deaths. Ostensibly collections of books, they often contain letters, postcards, pamphlets, receipts, programs, and other ephemera that are more commonly found among personal papers arranged by archival standards. The pages of the volumes within personal libraries can exhibit annotations by former owners consisting of a few sparse underlining marks or, in other cases, dense marginalia that constitute a layer of manuscript materials lying atop a bedrock of published works. The presence of ephemera and annotations may encourage a view of personal libraries as semiarchival collections whose constituent parts should be kept together like those in a manuscript group, perhaps in their original order. Yet the availability of item-level cataloging techniques that permit easy description and retrieval of individual books might just as reasonably lead to a conclusion that items in personal libraries should be intershelved with other books in special collections stacks. Possessing a hybrid bibliographic identity that incorporates aspects of both books and manuscripts, such libraries present unique cataloging and technical processing challenges to the institutions charged with caring for them and making them available for use and study.

Studies that focus on the literary and cultural significance of personal libraries are published with some frequency. Considerably less, however, has been written about the role of libraries in making these complex collections accessible to the public by means of item-level and collection-level cataloging records, finding aids, and other technical processing techniques. Whether personal libraries should be shelved together or apart in special collections stacks, classified by Library of Congress (LC) numbers or according to another scheme, cataloged with a full set of MARC fields capable of reflecting their unique characteristics or described less elaborately, with distinctive features noted on a holdings record: here the literature is perplexingly mum. The scarcity of such literature might be attributed to a view that the tradi-

1. All translations are by the author. 
tion of rare book and special collections cataloging, amply covered in the literature, adequately addresses whatever technical processing complexities personal libraries might present. But the intricate relationships that books in such libraries can have with each other, the manuscript-like materials they frequently contain, and the annotations that sometimes crowd their pages pose cataloging conundrums to which the conventions of rare book cataloging do not always provide secure answers and thus merit a more thorough discussion than they have up until now received.

This study does not intend to provide solutions to such cataloging quandaries or offer a prescriptive list of techniques that special collections departments should employ in all cases when cataloging personal libraries. Rather, it attempts to describe what special collections departments are doing now to make such libraries available to their patrons in catalogs and on Web sites. Presenting the results of a survey of 111 Association of Research Libraries (ARL) members regarding the methods they use in the technical processing of personal libraries, it offers a view of how special collections catalogers have handled some of the most common problems of description and arrangement that processing a personal library involves, from the choice of MARC fields and classification schemes to the storage of ephemera and the description of annotations. Because they are a subject of intense scholarly interest and because they exhibit the hybrid characteristics of personal libraries in a particularly marked way, this study has chosen to focus on the more narrow area of the libraries of novelists, poets, and dramatists, referred to throughout this essay as "creative writers," for lack of a better term. The conclusions that it draws are nevertheless applicable to the personal libraries of bibliographers, historians, artists, and other well-known people, which share many of the same characteristics. ${ }^{2}$

The object of the study is to encourage a greater awareness of what technical processing approaches are currently being used in special collections departments, not only among catalogers but also among curators, reference librarians, archivists, and other special collections staff, whose work all relies to one degree or another on the cataloging and archival descriptions of materials in our catalogs and on our Web sites. Such awareness may perhaps lead to a more informed consideration of what combination of methods seems to work best for making such libraries more accessible to patrons, the shared aim of public services staff and catalogers alike. And though the author of this article is far from advocating a homogenized, one-sizefits-all approach to the technical processing of personal libraries, it is to be hoped that such discussion may result in a more uniform treatment of these collections than public catalogs suggest they are receiving at present—and thus perhaps in

2. Indeed, survey respondents noted that the personal libraries of individuals who cannot comfortably be described as "creative writers" exhibit many of the same qualities as those of poets, novelists, and dramatists and are treated similarly. 
greater ease of use and study of personal libraries in our collections by those who rely on our catalogs to find and interpret them.

\section{Literature Review}

The personal libraries of creative writers, long considered to be of secondary literary importance to writers' personal papers, are now recognized as a fertile terrain for scholarly research due to the information they yield about writers' reading habits, their literary antipathies and enthusiasms, and the mysterious connection between their reading and their own work. ${ }^{3}$ Books in such libraries map the extent of writers' reading, showing where it was comprehensive and where it was less deep. Signatures and dedications of friends and colleagues on title pages trace the tangled network of writers' relationships with other writers and help identify their place in the larger literary culture in which they lived and wrote. Notes, letters, and ephemera tucked inside books provide vital links between authors' reading and writing and their life beyond the printed page. And the annotations that crowd the pages of their books - sometimes consisting of mere marks, sometimes taking the form of lengthy dialogues with the text—chart writers' experience of reading and thinking with a vivid immediacy. Such libraries function, in effect, as a kind of biographical shadow text that documents in striking detail the intellectual lives of writers as played out in the pages of books.

While scholarship devoted to the purely literary and cultural value of such libraries will not be of immediate interest to special collections staff charged with the acquisition and cataloging of personal libraries, a taste of some of it might nevertheless encourage a beneficial awareness of the conclusions that scholars can draw from annotations on a page, ephemera tucked in volumes, and the presence of a certain edition of a book in the personal libraries of writers and others-and thus a greater attentiveness to what aspects of books in personal libraries may need to be described in cataloging for the benefit of scholars. Useful examples of scholarship that explores the literary dimensions of personal libraries include studies of the private collections of Theodore Dreiser, ${ }^{4}$ Leo Tolstoy, ${ }^{5}$ Vladimir Nabokov, ${ }^{6}$ Andre Morellet, ${ }^{7}$ Richard Wright, ${ }^{8}$ Herman Melville, ${ }^{9}$ and Flannery O'Connor. ${ }^{10}$ Of these,

3. Alan Gribben provides a useful account of how the private libraries of writers have begun to receive the kind of scholarly attention devoted to authors' collections of private papers only fairly recently. See Alan Gribben, "Private Libraries of American Authors: Dispersal, Custody, and Description," Journal of Library History 21, no. 2 (1986): 300-14.

4. Roark Mulligan, “Dreiser’s Private Library,” Dreiser Studies 33, no. 2 (2002): 40-67.

5. Galina Alekseeva, "Describing Tolstoy’s Private Library,” Tolstoy Studies Journal 13 (2001): 98-107.

6. Gavriel Shapiro, "From Nabokov's Private Library," Nabokovian 42 (Spring 1999): 26-31.

7. Dorothy Medlin, “Andre Morellet's Library," Libraries \& Culture 31, issue 3/ 4 (1996): 574-602.

8. Michel Fabre, Richard Wright: Books and Writers (Jackson: University Press of Mississippi, 1990).

9. Wilson Walker Cowen, Melville's Marginalia (New York: Garland, 1987).

10. Arthur F. Kinney, Flannery O'Connor's Library: Resources of Being (Athens: University of Georgia Press, 1985). 
Roark Mulligan’s “Dreiser's Private Library” is particularly notable for the deft way it uses the writer's marginal annotations to trace the trajectory of his intellectual development. Michael Fabre's Richard Wright: Books and Reading and Arthur F. Kinney's Flannery O'Connor's Library: Resources of Being are essentially annotated booklists that describe significant features of the writers' books; in the case of Wright, excerpts from his own writings that relate to particular items in his library are also supplied, providing useful connections between the library and the author's own works. H.J. Jackson's superlative book-length study of readers' marginal annotations, Marginalia: Readers Writing in Books, ${ }^{11}$ the richest of the literary studies surveyed here, offers an analysis of marginalia found in the personal collections of Rupert Brooke, Samuel Taylor Coleridge, Hester Piozzi, and others and finds as much "continuity of practice" in book-annotating over time as "variations and evolution." ${ }^{12}$ Suggesting both the rich possibilities and limits of the scholarly study of annotations in the books of both the celebrated and the more obscure, Marginalia is an indispensable guide to this curious literary subgenre that flourishes within the pages of personal libraries and is essential reading for both special collections library staff and scholars who work with them.

Scholarship that examines the distinctive metatextual space that creative writers' personal libraries create through their mingling of texts by an owner's friends, associates, and literary forebears may also be of use to library staff who work with personal libraries, even if it is not immediately relevant to cataloging. Such studies may foster a more complex view of such personal libraries as a network of texts in which books by other writers and the former owner's own works are in some sense in dialogue with one another. Daniel Ferrer, emphasizing the fluid, relational aspects of writers' personal libraries, has described such collections as "transactional space[s] where books and manuscripts interact, where the book in the process of making itself is articulated on the already written." ${ }^{13}$ Examining the personal libraries of writers such as Emile Cioran, Francis Ponge, and Henri Michaux, Yves Peyré similarly finds that a writer's personal library is not a monolithic collection of books but a complex bibliographic galaxy made up of constellations of distinctive small sublibraries, each of which serve a particular purpose in a writer's life and work. ${ }^{14}$ Though they do not address the role of librarians in making the bibliographic labyrinths of personal libraries more accessible to the public, studies like Ferrer's and Peyré's nevertheless encourage a more nuanced approach to the technical processing of such collections that is as attentive to the relationships between books as it is to their individual features.

11. H.J. Jackson, Marginalia: Readers Writing in Books (New Haven, Conn.: Yale University Press, 2001).

12. H.J. Jackson, Marginalia, 17.

13. Daniel Ferrer, "Un imperceptible trait de gomme de tragacanthe," in Bibliothèques d'écrivains, ed. Elisabeth Décultot, Paolo D’Iorio, et Daniel Ferrer (Paris: CNRS Editions, 2001): 15.

14. Yves Peyré, "L'écrivain et sa bibliothèque," BBF 47 (2002): 12-20. 
Alan Gribben's "Private Libraries of American Authors" appears to be the first study to recognize the crucial connection between literary scholarship centered on personal libraries and the custodianship of such libraries by academic institutions that makes such research possible. Describing the loss and dispersion of large portions of several American authors' libraries due to the carelessness of family members and literary executors, Gribben urges scholars and librarians to do a better job of educating "families and estates about the scholarly value and proper care of books as artifacts and the advantages of making these assets available for scholarly purposes in a well-maintained academic environment." ${ }^{15}$ Gribben focuses principally on the descriptive annotated book catalogs and book-lengths studies of authors' books and reading that literary scholars produce and refers only in passing to the more workaday cataloging tasks performed by special collections staff. Nevertheless, acknowledging the close relationship between the literary study of authors' libraries and librarianship, he describes such studies as a "borderline area between literary studies and library science" and advises professional librarians and literary scholars to team up for "joint efforts" on scholarly projects involving such libraries. ${ }^{16}$ His counsel might apply equally well to the more basic efforts of cataloging and description that special collections department members undertake when processing personal libraries, which could surely benefit from the insights of literary scholars who specialize in the work of the authors who once owned them.

More recently, Anna Manfron, writing in Bollettino, has offered what is the most thorough analysis of the technical issues involved in the processing of personal libraries to date. ${ }^{17}$ Conceiving of the personal library of a writer almost Platonically as an organic unity whose special character should be protected through all phases of acquisitions and cataloging, Manfron describes some of the technical steps libraries need to take to realize this objective. Noting that dispersion of the library must be avoided at all costs before transfer, she states that the "maintenance of the [library's] unity must be guaranteed in an explicit way" by being treated as a "separate fonds," not simply through the creation of cataloging records that collocate the library's contents virtually but by shelving books physically together, preferably in "an arrangement that suggests the original one." ${ }^{18}$ In addition to recording special features of books — bookplates, dedications, signatures—in the notes area of bibliographic records, ${ }^{19}$ Manfron recommends that libraries provide other tools of access to patrons: topographical maps of the collection, for instance, for scholars who are permitted direct access to the stacks, and an introductory note that offers a history of the collection and its organization and of the "characteristic

15. Alan Gribben, "Private Libraries of American Authors,” 302.

16. Ibid., 310.

17. Anna Manfron, "Le biblioteche degli scrittori," Bollettino 44, no. 3 (2004): 345-58.

18. Ibid., 347.

19. Ibid., 349. 
principles of the documents that comprise the fonds." ${ }^{\prime 20}$ All such procedures should be undertaken with the aim of preserving and making explicit the special character of the personal library for the public.

Though her remarks about the personal library as fonds are striking, Manfron's most important insight for special collections staff is likely her perception that the mélange of books and nonbook items such as cards, appointment cards, manuscript pages, and letters found in an author's books constitute not merely a library but, in effect, a set of personal papers or, in Manfron's phrase (borrowed from scholar Nazareno Pisauri), an "archive-library" that requires archival as well as cataloging techniques. ${ }^{21}$ The "techniques of cataloging and organization," she writes, "must be accompanied by, [and] often yield place to, the principles and techniques of the archivist" for heterogeneous collections like personal libraries that incorporate books as well as manuscript materials, published items as well as unpublished. ${ }^{22}$ Drawing on relevant sections of AACR2 (Anglo-American Cataloguing Rules) and a guide issued by the ICCU (Istituto Centrale per il Catalogo Unico) for evidence that a collection of materials associated with a person can be described on one record, Manfron sketches out a tiered system of description for personal libraries that combines "piece by piece" cataloging of individual books with archival description at the collection or series level for the library as a whole or substantial portions of it. ${ }^{23}$ But while she writes that current database technology can make such a layered archival/ bibliographic system of description possible, Manfron acknowledges that standards for recording and sharing such information among different institutions are presently lacking. ${ }^{24}$ In the absence of such standards, individual libraries in Italy and in North America are, for the time being, left to devise solutions to cataloging personal libraries on their own, drawing on elements from the archival description and book cataloging traditions as they see fit.

One possible first step toward establishing such shared standards for cataloging personal libraries might be examining the particular strategies that special collections departments are using today to catalog and describe them. While a descriptive summary of the MARC fields, classification systems, methods of handling of ephemera, and mixtures of collection-level and item-level records employed by special collections departments today will not yield a ready-made set of standards for the cataloging of personal libraries, such an account may have the salutary effect of bringing to light cataloging procedures that have mostly been invisible except through the somewhat veiled medium of public library catalogs. A greater

\footnotetext{
20. Ibid., 347.

21. Ibid., 350 .

22. Ibid., 350 .

23. Ibid., 352 .

24. Ibid., 352-53.
} 
awareness on the part of special collections catalogers and administrators of the methods that other libraries are using to establish bibliographic control over these often unwieldy collections may in turn help foster a shared understanding of what procedures are most common and most effective and perhaps eventually may lead to an informal consensus on best cataloging practices.

\section{Survey and Methodology}

A survey of 10 multiple choice and free-answer questions concerning the technical processing of personal libraries of creative writers was sent to special collections catalogers, or, when such contact information was not available on library Web sites, to special collections administrators at 111 ARL institutions. A total of 46 institutions responded to the first survey, of which 35 (76\%) reported owning personal libraries of creative writers. A follow-up survey that asked for more detailed answers to eight additional questions about more complex technical processing situations involving personal libraries was next sent randomly to 15 respondents to the initial survey, of whom five returned answers. The questions for the first and the follow-up survey, both of which were delivered via the Survey Monkey Web tool, are available in the appendix of this article.

The intent of the first survey was to gain an understanding of the prevalence of personal libraries at ARL institutions and a general sense of the procedures used in the technical processing of them, from arrangement and description to the representation of the personal libraries in OPACs and library Web sites. Respondents who indicated that their libraries owned a creative writer's personal library were asked about shelving practices for personal libraries, the nature of the classification system used, and the combination of approaches - catalog records, descriptions on library Web sites, collection-level records, other non-MARC databases-employed to make such libraries visible to the public. Libraries that reported creating catalog records for personal library books were additionally requested to describe the MARC fields they used to record library owners, signers, annotators, library names, bindings, and other information associated with authors' copies of books. Concluding questions of the survey asked for information about institutions' methods of storing ephemera found in books, the description of annotations, and the existence of written procedures for cataloging personal libraries in special collections departments.

The second survey asked for more discursive responses to questions that attempted to uncover the rationale underlying decisions to class personal library books together or separately, keep ephemera in the books in which they are found or apart, and describe library books at a lesser or fuller degree of detail. Other questions inquired about trickier cataloging issues that can arise due to the presence in a 
library's collection of an author's papers in addition to his or her personal library and personal libraries donated by living writers. The second survey also asked respondents to provide general caveats or advice to libraries that are cataloging a writer's personal library for the first time.

\section{Results}

Survey results indicate that while many of the 35 institutions that reported owning personal libraries of creative writers employ many of the same general cataloging and classification techniques, there are nearly as many differences in

\begin{tabular}{|l|c|}
\hline $\begin{array}{l}\text { Table 1. ARL Institutions } \\
\text { That Report Owning Personal } \\
\text { Libraries of Creative Writers }\end{array}$ \\
\hline Response & Number/Percentage \\
\hline Yes & $35(76.1 \%)$ \\
\hline No & $11(23.9 \%)$ \\
\hline \multicolumn{2}{|c|}{ Total Responses: 46 } \\
\hline
\end{tabular}
practice as similarities, particularly where the use of MARC fields in bibliographic records is concerned. A slightly greater uniformity of approach is evident in the shelving and classification practices of responding libraries. Here too, however, variations are nearly as common. It appears that personal libraries share with the gallimaufry of other materials in the special col-

lections area a highly individualized bibliographic identity that resists standardized approaches and requires innovative, sometimes ad hoc cataloging techniques. The more variegated nature of special collections cataloging practices, which reflect both the diversity of special collections materials and the idiosyncratic traditions that special collections departments have developed over many years, may also account for some of the variation in the treatment of personal libraries. In some cases, a certain degree of unwieldy difference is probably inevitable: the heterogeneous nature of personal libraries demands it. In others, it may be that local cataloging traditions could be slightly standardized to provide more consistent access to personal libraries with no dulling of the distinctive local cataloging flavor on which many individual institutions pride themselves, as will be discussed later in this essay.

The results of the first survey can be most easily discussed by grouping them into nine areas: 1) shelving practices; 2) classification schemes used to arrange books; 3 ) methods used to make libraries visible to users in the library OPAC and on library Web sites; 4) OPAC home location codes assigned to personal library books; 5) MARC fields employed in cataloging; 6) the recording of the presence of annotations; 7) distinguishing copies of the same editions of books found in authors' libraries and in libraries' general collections; 8) the storage of ephemera; and 9) the existence of departmental cataloging procedures. Information gleaned from the second survey that relates to these nine areas is discussed in tandem with the results from the first survey. Additional information from the second survey concerning decisions about whether to catalog libraries with a lesser or greater degree of detail, special 
situations involving authors' personal papers and the libraries of living authors, and general caveats and recommendations are presented later in the article.

\section{Shelving Practices for Personal Libraries}

The results of this study reveal that Manfron's ideal of the physically integrated library is realized rather infrequently by the institutions surveyed. Only $12(34.3 \%)$ of the 35 institutions that reported on their shelving practices indicated that they shelve all personal libraries together in special collections areas. Nine $(25.7 \%)$ stated that intershelving personal library books with members of a more general collection of books in special collections stacks is the norm. The 14 (40\%) respondents who indicated that they use "other" shelving practices, meanwhile, described

\begin{tabular}{|c|c|}
\hline Shelving Practice & $\begin{array}{l}\text { Institutions } \\
\text { That Use }\end{array}$ \\
\hline $\begin{array}{l}\text { Personal Libraries Shelved } \\
\text { Together }\end{array}$ & 12 (34.3\%) \\
\hline $\begin{array}{l}\text { Personal Libraries Shelved } \\
\text { with Members of More } \\
\text { General Collection }\end{array}$ & 9 (25.7\%) \\
\hline Other Arrangement & $14(40 \%)$ \\
\hline
\end{tabular}
an irregular history of shelving personal library books together and apart due to a range of factors, including the size and provenance of the library, a stipulation in the deed of gift that requires physical collocation, and a past policy of shelving libraries together that has been abandoned more recently in favor of intershelving. It is possible that some or most of these libraries consider physical collocation to be the most desirable approach to organizing personal libraries. The results of the survey suggest, however, that extenuating circumstances often require different approaches to shelving, resulting in a patchwork of personal library collections shelved together and apart.

Two respondents to the second survey offered reasons why intershelving with a more general group of special collections books may be preferable to shelving libraries together in some cases. One respondent stated that now that electronic cataloging records can "bring the collection together intellectually," his or her institution no longer finds it necessary to create "physically discrete special collections" for personal libraries and has ceased shelving them together. Another respondent provided a somewhat more pragmatic rationale for intershelving books in personal libraries with members of a more general collection: public services staff can more easily retrieve books shelved in a single arrangement than books in Balkanized separate collections shelved according to different schemes.

\section{Classification Schemes Used for Personal Libraries}

More than half (19, or $54.3 \%)$ of the 35 institutions that responded to a question about classification schemes reported that they assign LC classification numbers to books in personal libraries, while one (2.9\%) indicated the use of Dewey numbers. 


\begin{tabular}{|l|c|}
\hline \multicolumn{2}{|l|}{$\begin{array}{l}\text { Table 3. Classification Schemes } \\
\text { Used for Personal Libraries }\end{array}$} \\
\hline Classification Scheme & $\begin{array}{c}\text { Institutions } \\
\text { That Use }\end{array}$ \\
\hline Library of Congress & $19(54.3 \%)$ \\
\hline Dewey & $1(2.9 \%)$ \\
\hline Order of Original Owner & $1(2.9 \%)$ \\
\hline Other & $14(40 \%)$ \\
\hline \multicolumn{2}{|c|}{ Total Responses: 35} \\
\hline
\end{tabular}

Another institution (2.9\%) reported that it arranges personal libraries in the order in which the author originally shelved it. Requiring meticulous planning and documentation prior to the transfer of a personal library from its original location to a special collections area, shelving a personal library in its original order appears to be an admirable goal that is difficult to achieve in reality.

Of the $14(40 \%)$ respondents who reported using other classification approaches, six use a non-LC, non-Dewey classification scheme. In two such cases, this system is numeric in nature, while one library reported shelving books in personal libraries alphabetically by main entry. Five such institutions, meanwhile, described using a modified system of LC or Dewey classification involving the use of a base number to which a unique identifier or collection code is then added. In at least one case, the base LC classification number used in this modified scheme is that assigned to the author in the "P" LC literature classification schedules. Another respondent noted that personal libraries acquired before his or her institution switched to LC classification have Dewey numbers while libraries added to the collection more recently are classified by LC. One institution reported assigning local classification numbers to personal libraries of American authors and arbitrary year/number call numbers to other personal libraries. Still another institution described a mixed practice of assigning LC numbers to some personal libraries in its collections while creating unique local hybrid numbers based on LC classification for others.

\section{Methods Used to Make Personal Libraries Visible to Users-OPAC Records, Finding Aids, and Other Methods}

Survey results indicate that the majority of institutions that reported owning personal libraries of creative writers create individual bibliographic records for personal library books in their libraries' OPAC and that many create finding aids for personal libraries as well. A total of 14 (41.2\%) of the 34 institutions that responded to a

\begin{tabular}{|c|c|}
\hline Method & $\begin{array}{l}\text { Institutions } \\
\text { That Use }\end{array}$ \\
\hline $\begin{array}{l}\text { Bibliographic Records in OPAC } \\
\text { Only }\end{array}$ & $14(41.2 \%)$ \\
\hline Finding Aid Only & $0(0 \%)$ \\
\hline $\begin{array}{l}\text { Cataloging Records for } \\
\text { Individual Books and Finding Aid }\end{array}$ & $14(41.2 \%)$ \\
\hline $\begin{array}{l}\text { Cataloging Records for Books in } \\
\text { Non-OPAC Type of Database }\end{array}$ & $0(0 \%)$ \\
\hline $\begin{array}{l}\text { Description of Personal Libraries } \\
\text { on Webpage; no OPAC Records, } \\
\text { Finding Aid }\end{array}$ & $0(0 \%)$ \\
\hline $\begin{array}{l}\text { Other Method or Combination of } \\
\text { Methods }\end{array}$ & $6(17.6 \%)$ \\
\hline
\end{tabular}


question about methods used to make personal libraries visible to the public said that the bibliographic records were the only means of access to the collection. Another 14 (41.2\%) reported the use of both bibliographic records in the OPAC and finding aids.

Of the six (17.6\%) respondents who reported using "other" methods of making libraries visible to patrons, three stated that personal libraries in their collections are represented not only by individual OPAC bibliographic records but by pages on a library Web site that describe each personal library's contents. One respondent described creating finding aids for some and bibliographic records for all personal libraries, while another reported creating collection-level records for uncataloged libraries that are then replaced by individual bibliographic records as the books are cataloged. Finally, another respondent noted that it had recently posted the contents of one author's library on the Web site LibraryThing.

\section{Type of Home Location Code Used in OPAC for Personal Library Books}

Institutions that create individual bibliographic records for members of personal libraries assign each book a home location code that denotes the particular physical collection of which the book is a member as well as a classifica-

\begin{tabular}{|l|c|}
\hline \multicolumn{2}{|l|}{$\begin{array}{l}\text { Table 5. Type of Home Location Code } \\
\text { Used in OPAC for Personal Library Books }\end{array}$} \\
\hline Location Code & $\begin{array}{c}\text { Institutions } \\
\text { That Use }\end{array}$ \\
\hline $\begin{array}{l}\text { Distinctive Home Location } \\
\text { Code }\end{array}$ & 11 (32.4\%) \\
\hline $\begin{array}{l}\text { General “Rare Book Room" } \\
\text { or "Special Collections" } \\
\text { Code }\end{array}$ & $23(67.6 \%)$ \\
\hline \multicolumn{2}{|c|}{ Total Responses: 34} \\
\hline
\end{tabular}
tion number that specifies its place within that collection. The home location may be as broadly defined as "special collections," or it may refer to a more specialized group of books within a larger special collections area-a specific personal library, for example. Though a more specific location code for a personal library will likely have little value for institutions that intershelve personal library books with members of a more general collection of special collections books, those that shelve such libraries together may find that such designations make personal libraries more easily discoverable in the OPAC, where they can be used to restrict catalog searches to books that share a common author library location name.

The results of the survey show that specific location codes for individual personal libraries are not used very frequently. More than two-thirds (23, or 67.6\%) of the 34 institutions that responded to a question about home location codes assign a general "rare book room" or "special collections" home location to personal library books in their libraries' OPAC. Only 11, (32.4\%) use a more specific home location code for personal libraries in their collections (for instance, "James Dickey Library"). 


\begin{tabular}{|l|c|}
\hline Table 6. MARC Fields Used in OPAC Bibliographic Records for Personal Library Books \\
\hline MARC Field & $\begin{array}{c}\text { Institutions } \\
\text { That Use }\end{array}$ \\
\hline 561 Ownership/Custodial History Field for Former Owner & $10(30.3 \%)$ \\
\hline 590 Local Note Field for Annotations, Bookplates, etc. & $28(84.8 \%)$ \\
\hline 655 Index Term Field for Bookplates, Annotations, etc. & $12(36.4 \%)$ \\
\hline 690 Local Subject Added Entry Field for Personal Library Name & $0(0 \%)$ \\
\hline 700 Personal Name Entry Field for Library Owner's Name & $13(39.4 \%)$ \\
\hline 710 Corporate Body Name Entry Field for Personal Library Name & $6(18.2 \%)$ \\
\hline Both a 700 Field for Owner's Name and a 710 Field for Library Name & $7(21.2 \%)$ \\
\hline 700 Personal Name Entry Field for Annotator, Signer, etc. & $11(33.3 \%)$ \\
\hline 790 and/or 796 Personal Name Fields with Former Owner's Name & $6(18.2 \%)$ \\
\hline Other Fields Not Listed Above & $19(57.6 \%)$ \\
\hline Total Number of Responses: 33 & \\
\hline
\end{tabular}

\section{MARC Fields Used in OPAC Bibliographic Records for Personal Library Books}

The selection of MARC fields for recording access points and notes in the bibliographic records for individual members of authors' personal libraries proved to be the area in which survey responses showed the least uniformity. Special collections departments seem to be using a wide assortment of access point fields for annotators, owners and signers, and note fields to describe physical and other characteristics of books. Some institutions are using a relatively small cluster of fields for personal libraries, while others are deploying a much more elaborate set of tags. Other libraries, meanwhile, prefer to record distinctive characteristics of personal library books in notes on holdings records.

Certain general trends and similarities in approaches can nevertheless be identified. A total of $28(84.8 \%)$ of the 33 institutions that responded to a question about MARC fields reported that they use a 590 local note field to record information about marginalia, bookplates, autographs, inscriptions, and the like. Twelve institutions (36.4\%) use the 655 field, generally designated for indicating the form or genre of materials being described, to record similar information about physical characteristics of books. Thirteen, or 39.4\%, add the library's former owner's name in a 700 personal name entry field along with a relator term indicating that the name is the former owner's, while $11(33.3 \%)$ also use the 700 personal name added entry field to record the names of signers, annotators, and other persons besides the library owner who are in some way associated with the book's production or use. Six respondents $(18.2 \%)$, meanwhile, prefer to use $79 \mathrm{X}$ local personal name added entry fields to record the name of the library owner and other persons associated with the book. Four (12.1\%) respondents who reported the use of "other" 
MARC tags indicated that they add a 541 gift and acquisitions field with information about the provenance of a book.

Survey results indicate that libraries differ widely in their choice of field for providing access for the "name" of a writer's personal library (that is, the overarching name or collective title that an institution gives to a particular personal library), surely one of the more important components of a MARC description. The most common field used for providing such access to the library as a whole seems to be the 710 corporate body added entry tag: six (18.2\%) respondents indicated that they add the name/ collective title of the library here. Other respondents seem to be using an assortment of tags for library name or collective title access. Two institutions (6.6\%) indicated that they place personal libraries' titles or names in the 793 field (local uniform title field), while one (3\%) institution each noted that the 590 (local notes), 730 (uniform title), 791 (local added entry for corporate names), 799 (local added entry for uniform titles), and 940 (undefined local field) fields are used for this purpose. Still another respondent reported adding personal library collective titles in a field reserved for subject headings (the 650 field, with the second delimiter value set at four to indicate an unspecified source) after years of placing them in a 690 local topical term field. Since not all of these fields are typically indexed in library OPACs, patrons at some institutions may have difficulty finding personal libraries through title searching alone.

It appears that the most common combination of MARC fields for recording information associated with an author's copy are a 590 local note field and/or 655 genre / form field for noting physical characteristics, a 700 (or, alternately, a 790 local field) personal name added entry field for the former owner's name, sometimes a 710 corporate name added entry or another field for the name/collective title of the library, and, somewhat less frequently, a 561 or 541 field for recording ownership or custodial history. Fourteen (42.4\%) respondents reported using a rough combination of these tags, while six (18.2\%) use 590s and 700s for physical characteristics and the name of the owner and other contributor names respectively without recording a personal library title. Three (9\%) appear to be using only 590 local note tags. Two $(6 \%)$, meanwhile, reported that they record the bulk of information about personal library books in notes in holdings records.

\section{Methods of Recording Information about Annotations in Personal Library Books}

The great majority of respondents indicated that they record the presence of annotations, those marginal jottings and markings that provide perhaps the most intimate record of a writer's relationship with the books in his or her library. A full $27(77.1 \%)$ of the 35 institutions that responded to a question about the recording 
of information regarding annotations in books reported doing so, either in the bibliographic record (18 or $51.4 \%$ of respondents) or in the holdings record (nine or $25.7 \%$ ), a result that does not quite square with responses to questions about MARC fields used, which indicate that only two institutions use holdings records to describe characteristics of

Table 7. Methods of Recording Information about Annotations in Personal Library Books

\begin{tabular}{|l|c|}
\hline Method & $\begin{array}{c}\text { Institutions } \\
\text { That Use }\end{array}$ \\
\hline $\begin{array}{l}\text { Information about Annotations } \\
\text { Recorded in Bibliographic Records }\end{array}$ & $18(51.4 \%)$ \\
\hline $\begin{array}{l}\text { Information about Annotations } \\
\text { Recorded in Holdings Record }\end{array}$ & $9(25.7 \%)$ \\
\hline $\begin{array}{l}\text { Information about Annotations } \\
\text { Recorded in Other Location }\end{array}$ & $5(14.3 \%)$ \\
\hline $\begin{array}{l}\text { Information about Annotations not } \\
\text { Recorded }\end{array}$ & $3(8.6 \%)$ \\
\hline \multicolumn{2}{|c|}{ Total Responses: 35} \\
\hline
\end{tabular}

books. Three respondents (8.6\%)

reported not recording the presence of annotations at all.

Of the five (14.3\%) surveyed institutions that indicated that they document the presence of annotations in some other place, one reported using notes on rare book slips or in finding aids for this purpose, while another described recording information about annotations in a non-OPAC database. Three institutions simply noted that they sometimes record annotations in bibliographic records in the OPAC but sometimes do not. Of these, one indicated the occasional use of holdings records for documenting the presence of annotations in books. The survey did not ask respondents to indicate what MARC tags they use for recording annotations in bibliographic records. (A 590 or 655 , for local notes and form/ genre terms respectively, would seem to be the most likely place to note such information.)

\section{Methods of Distinguishing Copies of Same Editions of Books Found in Writers' Personal Libraries and Other Library Collections}

More than half $(20$, or $57.1 \%)$ of the 35 institutions that reported on the methods they use to differentiate the same edition of a book found in both an author's personal library and elsewhere in their libraries' collections stated that the notes in the bibliographic record describing characteristics of the author's copy specify that they refer to that copy, while nine $(25.7 \%)$ reported that information specifically related to the author's book is recorded in the holdings record for that copy.

\begin{tabular}{|l|c|}
\hline \multicolumn{2}{|l|}{$\begin{array}{l}\text { Table 8. Methods of Distinguishing } \\
\text { Copies of Same Editions of Books } \\
\text { Found in Writers' Personal Libraries } \\
\text { and Other Library Collections }\end{array}$} \\
\hline Method & $\begin{array}{c}\text { Institutions } \\
\text { That Use }\end{array}$ \\
\hline $\begin{array}{l}\text { Notes about Owner's Copy } \\
\text { on Bibliographic Record } \\
\text { Distinguish Copies }\end{array}$ & $20(57.1 \%)$ \\
\hline $\begin{array}{l}\text { Information about Owner's } \\
\text { Copy Recorded on Its } \\
\text { Holdings Record }\end{array}$ & $9(25.7 \%)$ \\
\hline Other & $6(17.1 \%)$ \\
\hline \multicolumn{2}{|c|}{ Total Responses: 35} \\
\hline
\end{tabular}


Of the six (17.1\%) institutions that indicated the use of another approach, one reported that it downloads completely separate bibliographic records for each copy of the edition that it owns, one for the author's copy and one for any other copies in the library's collections. Notes about each copy are recorded in the bibliographic record. Another such institution indicated that information about the author's copy appears on the same screen as information about the main library copy but in separate bibliographic displays. A third respondent who reported employing "other" approaches described usage of both notes in bibliographic records and holdings records notes to differentiate copies, while a fourth reported adding notes to shelf list cards, holdings cards, and bookplates. Two responses were not germane to the question.

\section{Storage of Ephemera: Kept in Separate File or in Books?}

The presence of ephemera - that hodgepodge of programs, bus tickets, receipts, postcards, and other stray materials often found wedged inside the pages of an author's books - in personal libraries presents a storage dilemma for special collections units that house them. Though ephemera are ostensibly an integral part of personal libraries, keeping loose materials inside books involves the risk of their loss during use by patrons and, in the case of materials that are bulky or large in size, damage to books in which they are housed or indeed to the ephemera them-

\begin{tabular}{|l|c|}
\hline $\begin{array}{l}\text { Table 9. Storage of Ephemera: Kept } \\
\text { in Separate File or in Books? }\end{array}$ \\
\hline Storage Method & $\begin{array}{l}\text { Institutions } \\
\text { That Use }\end{array}$ \\
\hline $\begin{array}{l}\text { Ephemera Kept in Books in } \\
\text { Which They Were Found }\end{array}$ & $2(5.7 \%)$ \\
\hline $\begin{array}{l}\text { Ephemera Removed to a } \\
\text { Separate File }\end{array}$ & $18(51.4 \%)$ \\
\hline Other & $15(42.9 \%)$ \\
\hline \multicolumn{2}{|c|}{ Total Responses: 35} \\
\hline
\end{tabular}
selves. Relocating ephemera to a separate file, on the other hand, separates materials that are often intimately related to the books in which they are housed from their original context and may complicate their retrieval and use. Deciding what approach to take seems to require a careful weighing of the possible advantages and drawbacks of removing or separating ephemera from library books, often on a case by case basis.

Survey results indicate that $18(51.4 \%)$ of the 35 institutions that answered a question about the handling of ephemera opt to remove ephemera from personal libraries and store them in a separate file. Only two (5.7\%) reported keeping ephemera inside the books in which they are stored in all cases. The 15 (42.9\%) respondents who indicated using "other" storage approaches, meanwhile, reported sometimes keeping ephemera inside books and sometimes in a separate file, basing decisions on the possible damage that bulky or acidic ephemera might do to the books in which they are inserted, the presence of an author's papers in the special collections unit, and other considerations. Another institution reported that it is in the process of creating 
a separate file for personal library ephemera, which has evidently heretofore been housed with personal library books.

Respondents to the first survey who indicated an "other" method of storing ephemera and several respondents to the second survey described some of the factors that determine whether ephemera is stored with books or separately. One respondent described wrapping those materials that could comfortably fit in books in polyester film and storing others separately; another reported leaving ephemeral materials inside books except for particularly valuable materials (such as a note from a well-known writer), which are stored separately. Still another respondent described a practice of keeping ephemera that are closely related to the book in which they were found inside that book while removing other materials to a separate file. Two institutions, meanwhile, noted that if their special collections units owned an author's papers as well as his or her library, they preferred to keep ephemera with the papers.

\section{Existence of Written Rules or Procedures for Cataloging Personal Libraries}

Whether due to the complex nature of personal libraries or the infrequency with which such libraries are cataloged in many special collections departments, most institutions seem not to have created a standardized set of rules governing the cataloging of personal libraries in their collections. The majority of survey respondents indicated that they catalog personal libraries on a case by case basis, concocting a local vintage of standards consisting of AACR2 and DCRM(B) (Descriptive Cataloging of Rare Materials [Books]) rules blended with local practices; that set of standards is then adjusted to accommodate the distinctive attributes of each library. Of the 33 institutions that responded to a question about the existence of procedures in their departments, only one (3\%) reported creating a set of rules for each personal library it catalogs. One other respondent noted that his or her institution was in the process of drafting general procedures.

\section{Factors Influencing the Degree of Cataloging Detail for Personal Libraries}

Respondents to the second survey were asked to describe what considerations might lead to a decision to catalog a creative writer's personal library at a greater or lesser degree of detail. Two respondents cited the literary stature of a writer and a writer's strong personal connection to the institution's host university as factors that might encourage a greater thoroughness in cataloging, while another respondent indicated that a related manuscript collection in the library's possession could also be grounds for lavishing more cataloging detail on a personal library. Another institution, meanwhile, reported having outsourced the cataloging of a personal library that lacked 
annotations and other notable features and could thus presumably be cataloged at a more basic level. Such responses suggest that the precise array of cataloging fields chosen for the bibliographic records of a personal library may vary considerably depending on a range of factors, some of them related to the distinctive characteristics of the personal library books themselves and their owners, some having to do with a personal library's relationships with other materials in an institution's collections.

\section{Special Situations-Libraries That Own Authors' Papers as well as Personal Libraries; Personal Libraries of Living Authors}

The second survey asked respondents to describe how they handle special situations that can complicate the cataloging of authors' personal libraries, such as when institutions own both the personal papers and the personal libraries of writers and/or the libraries of still-living writers. In cases in which institutions own both personal libraries and personal papers of writers, three of the respondents to the second survey described creating a collection-level MARC record for the personal library books with a URL link to an online inventory for the author's personal papers, which in turn mentions the existence and shelving location of the personal library books. Another institution reported occasionally linking online finding aids for the author's papers with the individual bibliographic records for the author's personal library books in the OPAC.

Three institutions indicated that they own the personal libraries of living authors. Of these, one institution reported that it had experienced no difficulties in the cataloging or processing of personal libraries due to the restrictions that still-living authors sometimes impose on the treatment and use of their materials. Elaborating further, this institution noted that a still-living author was actually an asset to its special collections unit during cataloging, able to offer valuable guidance in deciphering cryptic inscriptions and autographs found in books. Another institution, however, perhaps wary of the complexities of negotiating with living donors, stated that it would not be inclined to accept the library of a still-living author.

\section{Caveats, Recommendations}

Those institutions queried in the second survey were asked to provide recommendations and caveats to libraries that are cataloging an author's personal library for the first time. One respondent recommended using macros as frequently as possible during cataloging to speed up the creation of added entries to bibliographic records. Another respondent, mindful of the numerous players who have a hand in the processing of personal libraries, emphasized collaboration, noting that a staff ample enough to process large collections, a coordinator who can draft guidelines and see the project through to its completion, and the cooperation of preservation personnel who may need to repair or provide enclosures for certain items are all essential. 
A third respondent intriguingly suggested making lists of unmarked and unimportant books that then can be weeded from the personal library. Mentioning the scarcity of space in most special collections units, the respondent commented that cluttering up shelves with undistinguished mass-market paperbacks of the kind often found in personal libraries is not in the best interest of libraries and that a list of such titles might satisfy the needs of researchers as effectively as physical copies. This respondent also emphatically recommended intershelving members of personal libraries with other books in special collections stacks rather than shelving them separately, thus making the best use of scarce space and avoiding creating confusion for public services staff.

Finally, one respondent noted that before undertaking the onerous task of cataloging members of personal libraries, special collections units should ask themselves whether individual library items possess characteristics that truly warrant the creation of individual bibliographic records. "If a personal library requires a very minimal level of cataloging," the respondent asked, "the pertinent question is why bother at all?" Indeed, for personal libraries that exhibit few annotations, inscriptions, and other markings and include few rare or distinctive books, it may be difficult to make the case that full-level cataloging of each member is needed or the best use of resources and staff time. In such cases, a Microsoft Access or Excel database may be a more appropriate place for recording information about personal library books than individual bibliographic records in the OPAC.

\section{Discussion}

The survey results reveal a striking degree of diversity in the ways in which special collections departments handle the technical processing of writers' personal libraries. Though there seems to be a shared preference for using LC call numbers over Dewey or other classification numbers, and a tendency to shelve personal library books together rather than with other books in special collections areas, the institutions surveyed for this study frequently part ways when it comes to the handling of ephemera and the methods used to make personal libraries accessible to patrons in catalogs and on library Web sites. Particularly striking is the variety of MARC fields that special collections areas employ when cataloging personal library books. Nearly all respondents reported using note fields to describe books' physical features. Yet surveyed libraries use a wide range of other MARC fields, displaying a particular heterogeneity when it comes to use of access point fields for representing the name of the library itself.

This diversity of practices is in some sense unsurprising. Like many materials in special collections, the personal libraries of writers are highly eccentric collections that require treatment tailored to their special characteristics. The complex battery 
of MARC fields that one institution applies to the single personal library in its collection may not be appropriate for all of the multiple personal libraries in another much larger institution's possession, particularly if they do not exhibit many markings, rare bindings, or other distinctive features . (Not all personal libraries, it is good to remember, possess the tantalizing goldmine of annotations and ephemera that some do.) Each special collections area, moreover, has its own distinctive "brand" of technical processing procedures that it has developed over time to suit the local needs of patrons and the type of materials it houses, or for less easily discernable reasons of tradition. Nevertheless, the diversity of practices, most marked when it comes to cataloging and the other methods that special collections employ to make personal libraries accessible to the public, does raise the question of whether a greater uniformity of treatment might be desirable, especially if it resulted in increased ease in the discovery, use, and study of such libraries by scholars.

A recent search of the OPACs of several institutions that own personal libraries of writers suggests that such libraries are not always easy to find, possibly due to some of the nonuniform cataloging and processing practices mentioned above. A good deal of searching is often necessary before an OPAC user stumbles upon a record of a book in a personal library. Even if a searcher manages to find records for some of the books by means of random keyword searches alone, she may find tracking down all of the bibliographic records difficult due to the absence of hyperlinked access points that collocate personal library members by the "name" or collective title of the library as a whole and by names of former owners. Consistently assigning library "name" tags (such as "James Dickey Library") and tags for names of former owners (often paired with a relator term that identifies that name as the former owner's) to all bibliographic records, a practice exemplified in figure 1, allows OPAC users to obtain a list of all books in a personal library by clicking on shared hyperlinked MARC fields in the record of any given member. The use of such access points also identifies personal library books as members of a distinctive collection and provides more reliable access to bibliographic records than descriptive terms in free-text note fields, which may or may not be picked up by OPAC users' keyword searches. Without such shared tags, the place of personal libraries in OPACs is that of a disaggregated scattering of books whose individual characteristics may be thoroughly described in records but whose special nature as a cohesive collection is invisible to users. Opportunities for discovery of personal library books are reduced, and the connections between them are obscured.

Some institutions may be understandably hesitant to add such fields to bibliographic records that represent copies of books in personal libraries as well as copies of the same edition in other library collections. Unlike free-text note fields, which can 
Personal author: Sillitoe, Alan.

Title: A falling out of love and other poems / by Alan Sillitoe.

Publication info: London : W.H. Allen, 1964.

Physical description: 56 p. ; $23 \mathrm{~cm}$.

Personal name: Sillitoe, Alan, inscriber.

Personal name: Hughes, Ted, 1930-1998 former owner.

Corporate name: Ted Hughes Library ( University. General Libraries)

Local note: Manuscript, Archives, and Rare Book Library copy has dust jacket; has presentation inscription: For Ted, All the best, Alan July 11th 1964; from the library of Ted Hughes.

$\underline{\text { Staff view }}$

Call Numbers for: GENERAL

1) PR6037.I52 F3 1 BOOK STACKS

2) PR6037.I52 F3 HUGHES 1 BOOK SPECIALCOL (nocirc)

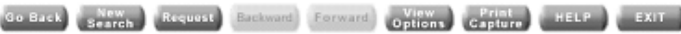

Figure 1. OPAC display of the bibliographic record for a book in Ted Hughes' personal library includes the "name" or collective title of the personal library in a 710 added entry field for corporate names and, in a 700 personal name added entry field, the name of the former owner with a relator term indicating that the name is the former owner's. Local notes in a 590 local note field describe characteristics of the personal library copy. An additional 700 personal name added entry field contains the name of the inscriber of the book. The name of the holding institution has been redacted.

be written in such a way as to specify that they describe features of one particular copy in the holding library's possession, access points in 700 (added entry for personal name), 710 (added entry for corporate name), and 730 (uniform title) fieldstags often used to record the names/collective titles of personal libraries and names of former owners-are not copy-specific and could conceivably cause some OPAC users to wonder why a personal library collective title tag appears, for example, on the bibliographic record for the copy in the regular stacks for which they are searching. Nevertheless, the benefits that such MARC fields provide in terms of collation and identification of personal libraries likely outweigh the drawbacks in many cases. For noteworthy, high-profile libraries, certainly, they would seem to be indispensable. However, libraries may wish to apply them more selectively to personal libraries that are small or deemed to be lacking in distinctive features.

The survey results reveal that libraries that assign access points for the collective title or name of a personal library most frequently use a 710 field, reserved for added entries for corporate names, for this purpose. Other libraries place names/ collective titles of personal libraries in MARC fields designated for local added entries for corporate names, such as the 791, in uniform title fields like the 730 , and occasionally in fields for local subject added entries like the 690. Since a personal library is a group of texts comprising works by multiple authors, the use of a corporate body tag for the name of a personal library makes a certain amount of sense from a cataloging perspective. Most catalog users, however, are unlikely to 
think of using a corporate author search to find a personal library or its individual members. Subject searches may also be counterintuitive to OPAC users on the hunt for a particular personal library. It is possible that placing phrases that designate the "name" or collective title of a personal library in a MARC field that is searchable by title rather than by author or subject—a 730 field, for instance-would allow OPAC users to locate personal libraries with much greater ease.

The survey shows that only a small number of respondents are assigning a distinctive home location code to members of personal libraries that are shelved together in special collections stacks. Allowing users to limit OPAC searches by shelving location to items in a specific personal library and, in many cases, to bypass entering search terms for data elements in the bibliographic record altogether, such codes provide an additional valuable means of collocating members of personal libraries in OPACs. (See figure 2 for an example of a distinctive home location code for a personal library in an advanced search menu.) They are strongly recommended for those libraries that shelve personal libraries together. However, distinctive home location codes are probably best used in combination with other MARC fields that identify books as members of a personal library and describe books' physical characteristics. Employing distinctive home location codes as the sole means of collocation and identification of personal library books, as a look at several OPACs suggests some institutions are doing, closes off a major route of discovery to patrons: that of searching for terms and access points within the bibliographic record itself.

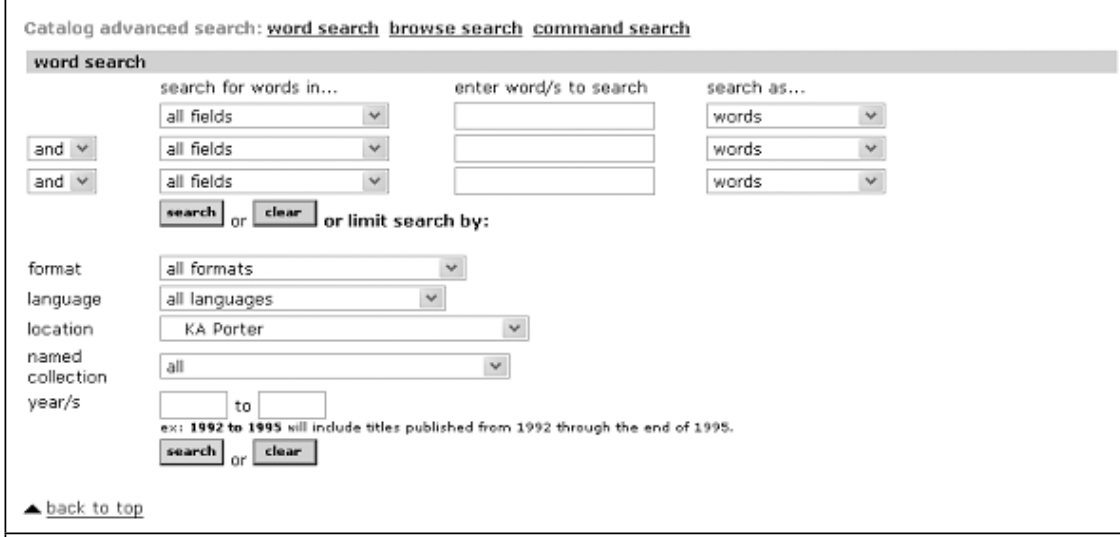

Figure 2. Distinctive home location code for library of Katherine Anne Porter allows users to limit searches to items within the author's library in the advanced search menu.

Libraries must obviously use their own discretion about the use and extent of notes to describe particular physical characteristics of books like signatures on title pages, marginalia, and ephemera, typically entered in 500 or 590 MARC note fields. In cases in which rich marginalia, ephemera, or other distinctive attributes are few or 
lacking, cataloging staff may justifiably conclude that adding such notes to bibliographic records of personal library books serves little purpose and opt for a quick, no-frills approach to processing them. Certainly, however, libraries should make every effort to document attributes of particularly distinctive personal libraries, using language that succinctly and unambiguously describes their characteristics. Recording the degree of detail and the location of marginalia in particular books, for instance, is more helpful to patrons than adding notes that simply indicate the presence of annotations, a term that can connote anything from light markings to rich marginal commentary. Even if they are not especially lengthy, notes describing presence of marginalia, signatures, dedications, and the types of ephemera contained within books can serve as invaluable guides to scholars and students who are mapping out a plan of study of a personal library, allowing them to quickly identify books that may possess rare or interesting attributes.

Anna Manfron suggests that the hybrid nature of personal libraries warrants a layered approach to the cataloging of personal libraries that combines item-level catalog records for individual books with collection-level records that provide a more comprehensive view of the library as a whole. The results of this study reveal that some surveyed institutions are already employing such an approach, perhaps due to a similar understanding that the contents of personal libraries straddle the realms of the bibliographic and the archival and require cataloging methods that partake of both the book and archival cataloging traditions. The Web pages and collection-level records found in the catalogs and Web sites of a number of the surveyed institutions may also reflect a simple realization that such tools allow for improved access as well as understanding of personal libraries. Collection-level records expand the possibilities for discovery of personal libraries by permitting users to approach them as collective entities, rather like the manuscript groups that they strongly resemble, as well as item by item. In addition to providing another means of access, pages that profile personal libraries on library Web sites can offer a more expansive description of such collections than MARC records permit and advice to users on what search strategies to use to find personal library books in OPACs. Finding aids can also provide similar benefits, though those that treat personal libraries as subsections of larger collections of personal papers often fail to provide the detailed descriptions that they merit and may not greatly improve access, particularly if no separate headings exist for personal library finding aids on special collections areas' finding aids Web sites. Along with individual catalog records for books, tools like these are strongly advised for libraries with personal libraries in their collections, at least for collections of particular distinctiveness or value.

If many of the libraries surveyed for this study seem to be treating personal libraries archivally as well as bibliographically, most do not seem to share Manfron's rather 
exalted view of the personal library as fonds. A good many respondents intershelve members of personal libraries with members of a more general collection. One respondent notably counseled discarding unremarkable paperbacks from libraries, a practice that makes a certain amount of sense but may appall those who view personal libraries as sacred unities that suffer violation when they are divided. Nonetheless, the survey responses do suggest that most institutions, much like Manfron, see the personal libraries of creative writers as eccentric entities that lie outside the tidier categories libraries devise for other materials. Made up of books, they also include archival materials such as ephemera; largely comprising published works, their pages, when marked, are in effect a species of manuscripts. The diversity of technical processing practices described here reflect this hybrid nature of writers' personal libraries - and, in many cases, the necessarily heterogeneous methods that must be employed to describe them accurately. It seems clear, however, that, in many cases, such heterogeneity could be tempered in the interest of improving access to personal libraries, at little cost to the institutions that care for them. Adding hyperlinked MARC access point fields for names/collective titles of personal libraries and former owners; assigning distinctive home location codes where possible; creating collection-level records, finding aids, and Web site descriptions in addition to item-level MARC records: such measures as these can transform personal libraries from fragmented, hard-to-find groups of books that are scattered throughout library catalogs into tightly integrated collections that users can easily locate and study.

\section{Conclusion}

In his essay "Le librerie personali nelle biblioteche pubbliche," Attilio Mauro Caproni writes that when a writer's personal library becomes part of a public collection, it passes from the realm of the "secret" to that of the "nonsecret," from a private space in which the library is a purely personal collection designed to serve the owner's artistic ends to a public space in which its "invisible," private aspects become "visible." ${ }^{25}$ These private, invisible aspects of the library are brought to light through the "systematic, conservation, and classificatory processes of library science"26 - in other words, through the technical processing work that special collections catalogers and other technical services staff perform when they add notes describing annotations and signatures, sort and store ephemera, and create descriptions of the library on a Web site or collection-level record. The technical processing of personal libraries, in Caproni's view, is thus a species of translation, a process of making the intensely personal relationship that a library owner has with his library understandable through the use of the standardized languages of description and arrangement developed by library and archival science. It is a view that is equally applicable to the

\footnotetext{
25. Attilo Mauro Caproni, "Le librerie personali nelle biblioteche pubbliche," Bibliotheca, n. 2 (2003): 269.

26. Ibid., 269 .
} 
personal libraries of scholars, artists, and other well-known people, which can be equally idiosyncratic and equally in need of elucidation by technical services staff in special collections areas.

Viewing the processing of the personal libraries as a tricky process of translation perhaps helps explain some of the diversity of cataloging approaches revealed in this study. Each personal library is a highly individualized bibliographic preserve that was assembled and arranged for private ends, not for public use. Its contents, marginalia, arrangement, and ephemera reflect the peculiar habits and personality of its owner. Representing the complex personal data that different personal libraries contain in a public language in which they can be easily understood will inevitably involve different choices of cataloging notes, MARC fields, finding aids, classification schemes, and storage practices-different descriptive vocabulary and different syntax, in other words. A standardized, one-size-fits-all approach to describing such libraries would clearly not do justice to the rich distinctiveness that they exhibit.

Nevertheless, personal libraries, for all their diversity, do share many basic elements. They include marginal notes and the signatures of former owners or of owners' friends. Tucked in their pages are postcards, letters, notes, bus tickets, and other stray mementos that link former owners' private lives of reading and thinking to the public lives they lead outside books. The books themselves have an assortment of bindings and editions and titles and languages. Given the many attributes that personal libraries that differ markedly in character and size have in common, it is probable that the technical language that we use to describe them could become less prone to idiosyncrasy and variation with no damage to the distinctive cataloging practices that individual special collections departments have developed over many years.

Due to their ambiguous, neither-fish-nor-fowl bibliographic identity, personal libraries will probably always elude easy cataloging and description. Special collections staff may at times have to settle for technical processing methods that leave the distinctive characteristics of personal libraries partly invisible. Despite catalogers' best efforts to link personal library books through notes, shared tags, and distinctive home location codes, the more complex ties between them may be beyond the descriptive powers of the MARC record. Nevertheless, this study suggests that a more consistent application of cataloging and technical processing techniques might bring these complex collections into much sharper focus for library users. Even if partial and incomplete, such efforts may have the welcome effect of making the mysterious worlds of personal libraries within special collections areas more available to the scholars and students who wish to explore them and thus ensure that these important parts of our cultural patrimony are as thoroughly studied and written about as the collections of personal papers and manuscripts in whose shadow they have frequently languished. 


\section{Appendix}

\section{Survey 1 Questions and Answer Choices}

1. Does the special collections unit of your library have any private libraries of creative writers (i.e., fiction writers, dramatists, poets) in its collections?

$\square$ Yes $\square$ No

2. Are members of private libraries of creative writers in your library's collections shelved together or intershelved with members of a more general collection?

- Shelved together

Intershelved with members of a more general collection

ㅇther arrangement (please specify)

3. Are the books in the private libraries of creative writers in your collections assigned Library of Congress or Dewey call numbers and shelved accordingly, or are they arranged according to some other scheme (e.g., author's own order)?

L Library of Congress classification numbers

Dewey numbers

Order of original owner

ㅇther arrangement (please specify)

4. How does your library make the books in the private libraries of creative writers in your collections visible to library patrons?

Cataloging records for the individual books in private libraries in your library's OPAC only

ㄱinding aid only

- Cataloging records for individual books and finding aid

- Cataloging records for individual books in a Microsoft Access or other similar database but no cataloging records in OPAC or finding aid

Description of private libraries on library Web site but no cataloging records or finding aid

$\square$ Other method or combination of methods not listed above (please specify)

5. In your library, have the books in creative writers' private libraries been given their own distinctive "home location" in the OPAC (e.g., "Special CollectionsJames Dickey Library"), or are the books given a general "special collections" or "rare book room" home location code? Please choose the option that most accurately describes your library's approach to home location coding.

B Books in private libraries have a distinctive home location in the OPAC

口 Books in private libraries have a general "rare book room" or "special collections" home location in the OPAC 
Q Question is not applicable because my library does not create bibliographic records in the OPAC for books in private libraries

6. If your library creates individual cataloging records for the books in the private libraries of creative writers in your collections, which of the following MARC cataloging fields has your library used to describe characteristics of the books?

口 561 ownership and custodial history field to indicate former owner

口 590 local note field to indicate presence of marginalia, bookplates, autographs, inscribing, ephemera, original wrappers, etc.

- 655 index term-genre/form field for recording presence of bookplates, annotations, etc.

- 690 local subject added entry field for recording private library name (e.g., "Samuel Beckett Library")

口 700 personal name added entry field with private library owner's name and a relator term in a subfield to indicate former owner

- 710 corporate name added entry field with name of author's library (e.g., "Ellen Glasgow Library (South Virginia University. General Libraries)")

- Both a 700 field for former owner's name and a 710 field for name of library

- 700 personal name added entry field with personal name heading for an annotator, signer, etc., and a relator term in a subfield indicating annotator, signer, etc.

- 790 and/ or 796 personal name local added entry fields with former owner's name and relator term to indicate former owner

$\square$ Question is not applicable because my library does not create bibliographic records in the OPAC for books in private libraries

- Other fields not listed above (please describe)

7. If your library owns other copies of the same edition of books found in an author's private library, do you have some method of distinguishing information about the author's copy from information about other copies in your library's collections in the bibliographic record for the books (e.g., making notes about characteristics of author's copy in the item/holdings record for that copy in the OPAC, specifying which copy notes in bibliographic record refer to, etc.)? Please describe.

- Notes about author's copy in bibliographic record specify what copy is being referred to

Information about the author's copy is recorded in the holdings/item record for that particular copy

Question is not applicable because my library does not create bibliographic records in the OPAC for books in private libraries

My library uses another method of distinguishing information about author's copy from information about other copies (please specify) 
8. Does your library keep ephemera/inserted materials in books in private libraries in which they were found, or does it remove the ephemera to a separate file? Ephemera are kept in books in which they were found

$\square$ Ephemera are removed to a separate file

O Other (please specify)

9. Does your library make a point of recording information about annotations/ marginalia found in books in the private libraries of creative writers either in a bibliographic record in the OPAC or in some other place?

- Information about annotations/marginalia recorded in bibliographic records in library OPAC

I Information about annotations/marginalia recorded in holdings/item record for author's copy

- Information about annotations/marginalia not recorded

- Information about annotations/marginalia recorded in some other place (e.g., Microsoft Access database). Please describe.

10. Does your library have an established set of rules and procedures that catalogers follow when they catalog books in the private libraries of creative writers, or do the cataloging approaches that your library uses vary depending on the nature and extent of the library being described? Please explain. 


\section{Survey 2 Questions}

1. Does your library own several different private libraries of creative writers? If so, have the distinctive characteristics of one private library ever led you to employ a specialized set of cataloging techniques and practices that you did not necessarily use when cataloging another private library? Could you give an example or two of how you tailored cataloging approaches to accommodate the idiosyncrasies of a particular library?

2. Could you describe some of the factors that have resulted in a decision by your library to catalog a creative writer's private library at a somewhat greater or lesser degree of detail (e.g., writer's special relationship with institution, size of library, completeness of library, writer's stature, rareness/ distinctiveness of books in the library, etc.)?

3. What factors have influenced your library's decision to class/shelve members of a creative writer's private library together or separately?

4. How does your library decide whether to keep ephemera in books in private libraries in which they were found or remove the ephemera to a separate file?

5. Does the special collections unit of your library own both the personal papers and the private libraries of any creative writers? If so, did the presence of the writer's papers in your collections help determine in any way the selection of techniques and degree of detail used in the cataloging of the writer's private library and the materials associated with it (ephemera, etc.)? Are the finding aids/cataloging records for the books and for the papers coordinated or linked in some way?

6. Does the special collections unit of your library own any private libraries of creative writers who are still living? If so, has this fact and the restrictions that still-living donors sometimes impose on the use of their materials influenced your decisions about how to catalog the writers' private libraries? How so?

7. Does the special collections unit of your library own any private libraries of persons who cannot comfortably be described as "creative writers"? If so, would you say that your library's cataloging of these libraries differs in any notable respects from your cataloging of the private libraries of creative writers?

8. What general recommendations (caveats, cautionary advice) would you give to special collections units of libraries that are cataloging a writer's private library for the first time? 